\title{
The Role of Indonesian Caregivers' Nonverbal Elements and Face Threatening Acts toward the Aged
}

\author{
Putu Dewi Merlyna Yuda Pramesti \\ Faculty of Language and Arts, Ganesha University of Education, Bali, Indonesia \\ N.L. Sutjiati Beratha \\ Faculty of Letters, Udayana University, Bali, Indonesia \\ Made Budiarsa \\ Faculty of Letters, Udayana University, Bali, Indonesia \\ I Nengah Sudipa \\ Faculty of Letters, Udayana University, Bali, Indonesia
}

\begin{abstract}
This study aimed at finding out the role of Indonesian caregivers' nonverbal elements and its relation to the face saving of the aged. This study was part of the author's dissertation research that took the theme of Indonesian caregivers' language politeness when they worked as caregivers for the aged in Japan. In this article the concept introduced by Brown \& Levinson $(1978,1987)$ on FTA (Face Threatening Act) is used as the concept in the process of analysis beside the concept from Ekman and Friesen (1969) on nonverbal language. Qualitative method was used in this study and the data used were primary data in the form of the Indonesian caregivers' utterances in their communication with the aged. The Indonesian caregivers who were used as the subjects consisted of 68 and all of them worked in the regions of Yokohama, Toyohashi, and Okayama. From the data analysis it was found that there were 11 types of nonverbal language which belonged to the emblems group, namely (1) eye contact, (2) smiling, (3) holding hand, (4) leaning forward, (5) lowering body position, (6) affirmative nodding, (7) gesture, (8) hugging, (9) patting shoulder, (10) interpersonal space, and (11) therapeutic touch. From the result of the analysis of the interviews with the aged it was concluded that all of these eleven nonverbal elements did not threat the faces of the aged and the use of the nonverbal elements could play the role as a mitigation of the threat towards the faces of the aged.
\end{abstract}

Index Terms - nonverbal language, Indonesian caregivers, saving the faces of the aged

\section{INTRODUCTION}

Language is a means of communication and interaction in society. Not only does one have to consider words or verbal elements, but one has also to consider other elements. The elements which are not less important to be considered are the nonverbal elements of the interlocutor that one has to understand. Nonverbal elements can take the form of eye contact, facial expression, gesture, voice, and touch. They have a very significant role in communication. This is caused by the fact that the nonverbal elements can "talk or speak "more than the verbal language.

Japanese do not express their true feelings very much when communicating. Generally, they are not of an expressive type of people when they are talking. It means that they can hide their true feelings, but it does not mean that they do not use nonverbal language at all. There are some gestures which are often used by Japanese when they are communicating. The gestures performed contain meanings which have to be understood by the interlocutor at the time of speaking in such a way that he or she can understand the Japanese ideas and the communication process can be effective and fluent. The studies on nonverbal elements have been conducted by many linguists.

\section{REVIEW OF LITERATURE}

\section{A. Face Threatening}

Face threatening is an act which can be verbal and nonverbal which is directed to threaten other's self-image in front of the public (Brown \& Levinson, 1978, p. 66). They say that face is a self-image in front of the public which everyone desires to have. There are two kinds of face, namely positive face and negative face. Positive face is the desire to be liked, respected, and recognized by other people. Negative face is the desire of every human not to be disturbed and that others do not keep him or her from getting what he or she wants. This concept of face applies universally. In addition, 
the participants in communication cooperate in face saving each other since t the faces of both parties are vulnerable.

According to Brown \& Levinson, in a communication one cannot avoid face threating, which is an action that harms the face of the speaker by opposition. However, the expression of this face threating act can be done more politely by minimizing the pressure of the face threat. A face threat is done because of three desires (Brown \& Levinson,1987, p.73), as follows:

1. The desire to express the face threat;

2. The desire to be efficient and to immediately express the face threat; and

3. The desire to keep maintaining the interlocutor's face at a certain level.

The same thing on the concept of face is also expressed by Cutting (2008, p. 43):

"In order to enter into social relationship, we have to acknowledge and show an awareness of the face, the public self-image, the sense of self, of the people we address. It is an universal characteristic across cultures that speakers should respect each other's expectations regarding self-image, take account of their feelings and avoid Face Threatening Acts (FTAs)."

The need for face is regarded to apply in all levels in culture and face is formulated as something which can be lost, so that it needs to be maintained, or to be supported. The assumption which underlies this theory is that face is continually in a risky condition since all forms of speech act which are called face threatening acts (FTAs) that have the function of connecting the speaker and the interlocutor are considered as a threat to the interlocutor. Hence, all actions of face threatening have to be neutralized by using appropriate good manners. Exactly, good manners are understood as the basis in producing a social system and are the means for facilitating interactions.

\section{B. Gestures}

Communication does not only use verbal language but needs nonverbal language to support the fluency of communication as the realizations of emotions, intentions, and purposes which are implicitly expressed by the speaker and the interlocutor. Physical movements in the ethics of speaking are the forms of the communication of meanings or intentions in speaking that consist of kinetic movements: facial expression, eye movement, standing position, hand movement, shoulder movement, head movement, and proximity and body movement of the speaker and the interlocutor in speaking (Chaer, 2010, p. 8).

In a social interaction, language plays an important role. In addition, nonverbal sign system has the same function as the verbal sign system which is also used. There are two types of system of nonverbal signs, namely nonverbal sign system which is always attached to the verbal sign system such as intonation, intensity, and voice timbre. The second nonverbal sign system consists of facial expression, body movement which is known as proxime. The nonverbal sign system belongs to kinesiology (Simpen, 2008, p. 34).

All of these are known as kinesics (Wharton, 2009). The elements above are important visual elements. Usually the information can be easily understood through the meanings expressed by the kinesics.

Ekman and Friesen (1969) divide kinesics into five parts as follows.

a) Emblem, that is, a nonverbal action that has a direct verbal translation such as greeting and the hand movement to show that one allows or approves.

b) Illustrator, that is, illustrative movements which accompany speech.

c) Affective, that is an attitude that reflects a change in facial expression that indicates pleasure, surprise, and displeasure.

d) Regulator, that is the attitude to maintain and regulate the actions of the speaker, for example, in order he or she or the listener always look enthusiastic.

e) Adaptor, that is the sign that is scientifically attached to body movement, such as the wrinkle of the forehead, eye movement, and the curl of the lip.

Wharton (2009, p. 139-149) in his book entitled Pragmatics and Non-Verbal Communication also states the same thing as his predecessors or Ekman and Friesen (1969) that kinesics includes gesture, which is the important part in communication process. Wharton in his book also divides kinetic movements into five types as emblem, illustrator, affective, regulator, and adaptor.

Hamiru (2004) in his book entitled 70 Japanese Gestures No Language Communication explains that Japanese is a language that is difficult to learn. Many people believe that Japanese uses body movements and minimizes utterances in communication since there are 120 gestures that are generally used. However out of the 120 gestures only 70 that are still used up to now. Some gestures that are used in Japan nowadays have been much influenced by the western world. In that book, Hamiru divides gestures into three groups, namely general gesture, slang gesture, and children's gesture.

Givens (2002, p.7-87) in e-book The Nonverbal Dictionary of Gestures, Signs, and Body Language Cues divides nonverbal language into some groups. For example, hand movement, gesture, self-touch, facial expression, head movement, , tone of voice, shoulder movement, touch, lip movement, and body movement.

In the book entitled Gaikokujin no tame no Kaigo Fukushihi that was published by Asosiasi Berbadan Hukum Umum Pertukaran Internasional dan Pendukung Bahasa Jepang (General Cooperate Body Association of International Exchanges and Support of Japanese) in 2011, the types of nonverbal language that appear in an interaction between a caregiver and the aged are explained in detail. The types of nonverbal language include body movement, gesture, facial expression, smile, hand movement, touch, and head movement. 
The nonverbal language which would be investigated in this study was limited to caregivers' body movements in general at the time of communicating with their aged patients, and mimics and attitude shown by the aged in the form of responses in the communication activity.

To analyze these comprehensively, every problem was presented separately in every chapter. The analysis was done holistically and completely using theories that have been explained in an integrated manner.

\section{Methodology}

\section{A. Participants}

The subjects of the study consisted of 68 Indonesian caregivers who worked in three regions in Japan (Okayama, Toyohashi, and Yokohama). The Indonesian caregivers who were the informants came from various regions in Indonesia such as Java, Sumatra, and Bali. All the informants who had JPPT N3 certificates, and JLPT N3 certificates and national nurse licenses spoke Indonesian as their mother tongue. There were 63 female caregivers, and 5 male caregivers of 68 subjects of the study. The age requirement for selecting informants was that the candidates have to be 18 to 30 years old. In one day, a caregiver works for 6 hours, subject to the shift division in the old age home where he or she works. On the other hand, the old informants selected were old patients aged from 65 to 105 , with the lightest to the heaviest care.

\section{B. Data Collection}

Data collection was done using some methods, namely observation method done using recording technique or by recording interactions between the caregiver and the old people, in order to see the use of nonverbal elements to see the use of nonverbal signs by the caregivers in communicating with the aged or the other way around. Data produced were in the form of pictures containing nonverbal elements used by the caregiver when communicating with the aged. Other methods include interview, done by in-depth interview by interviewing the caregiver and the aged. This in-depth interview aimed at tapping things related to the topic of the study which could not be found by referring to the result of the video recording. The interview with the aged had the aim of knowing the response of the aged to the application of nonverbal language by the caregiver.

\section{RESUltS AND DisCUSSION}

As explained by Pranowo (2009, p. 80), nonverbal elements that influence politeness include body movement, eye movement, head shake, hand raising, etc. From the five elements of nonverbal language explained by Ekman and Friesen (1969), namely emblem, illustrator, affective, regulator, and adaptor, only emblem which was found to have been used by Indonesian caregivers when they communicated with the aged. From the observation of the video of conversations between Indonesian caregivers and the aged 11 types of nonverbal language were found which belonged to emblem group, namely (1) eye contact, (2) smiling, (3) holding hand, (4) leaning forward, (5) lowering body position , (6) affirmative nodding, (7) gesture, (8) hugging, (9) patting shoulder, (10) interpersonal space and (11) touch. The discussion of the meanings of the nonverbal elements will be accompanied by the video recording of the interactions between the Indonesian caregivers and the aged. Then, a general explanation will be given which is related to the meanings of the nonverbal elements by relating them to the analysis of the speech context of the video, and matching them with the dictionary meanings of the nonverbal language (Givens, 2002).

\section{A. Eye Contact}

The following is the presentation of the picture taken from the video recording of an interaction between an Indonesian caregiver and and aged patient. The context of the situation of the speech occurred at the time an Indonesian caregiver approached an aged patient who was enjoying her food in the dining room.

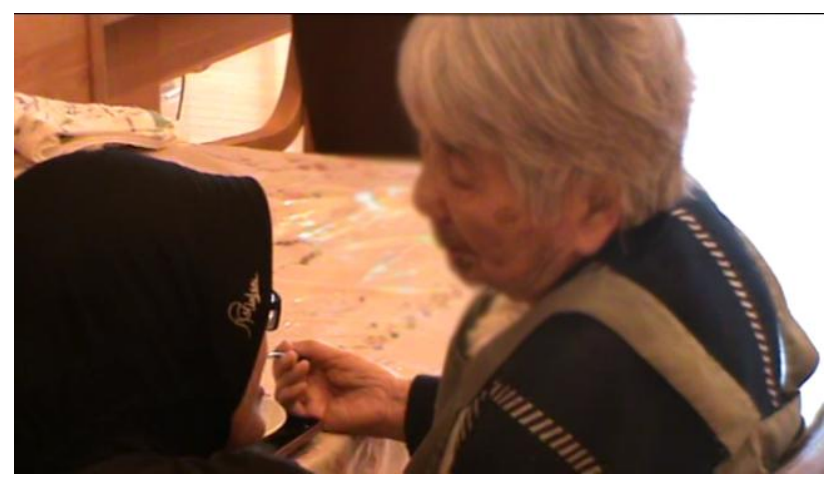

Figure 4.1 Eye Contact

The caregiver is seen to be squatting in front of the aged patient, while asking whether the lunch was delicious or not. 
In the domain of the nursing of the aged to see the eyes of the aged is a type of nonverbal language that is often used to attract the aged's attention and to show one's attention to the aged. This nonverbal element is effective in various situations since the aged gives a response to the caretaker's speech. This according to the explanationin the book entitled Gaikokujin no tame no Kaigo Fukushihi published by Asosiasi Berbadan Hukum Umum Pertukaran Internasional dan Pendukung Bahasa Jepang (General Corporate Body Association of International Exchanges and Supporter of Japanese) in 2011, and the result of an in-depth interview with the Indonesian caregiver. From the result of the interview, the Indonesian caregiver stated that they always use eye contact as a way to keep the aged focus on what the caregiver talked about.

\section{B. Smiling}

This nonverbal element is a friendly face expression (not a laughter).

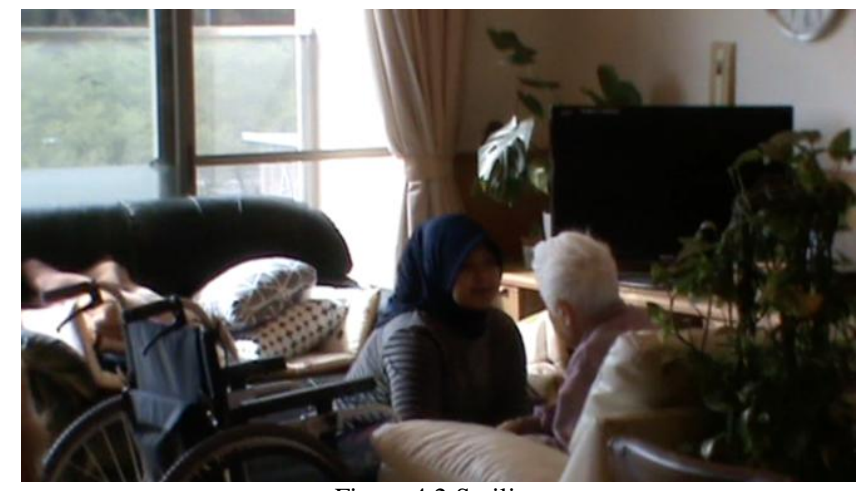

Figure 4.2 Smiling

In the domain of the nursing of the aged, smiling is the important activity which a caregiver has to always do in any speech context. By looking at the smile of a caregiver who is nursing him or her, the aged will feel comfortable (reducing the feeling of being intimidated) so that the communication process will develop harmoniously.

In Figure 4.2 an Indonesian caregiver is seen to be smiling at the aged before putting on his shoes. In the recording it appears that the Indonesian caregiver was offering to the aged to take a rest in the room after the lunch was over. Before taking the aged to the room, the caregiver offered to help him put on his shoes while smiling. The aged was nodding to show his approval.

Smile according to Givens, David (2002, p. 17) can describe many things such as emotional feelings, mood and the speaker's politeness. Gilbert (1993) in his study on the use of nonverbal language in a nurse and patient interaction found that a smile can bring forth calmness and comfort, and to keep a good relationship Caris-Verhallen et.al.,1999).

\section{Holding Hand}

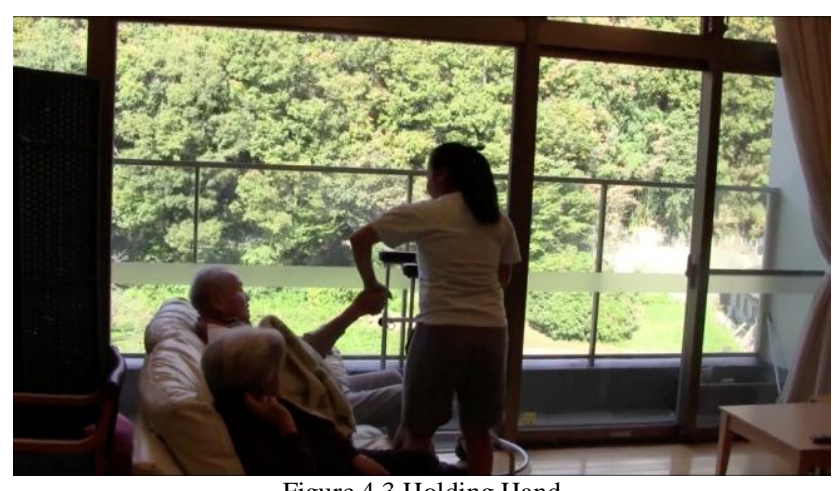

Figure 4.3 Holding Hand

This nonverbal language is a movement to hold hand as a manifestation of love expression. In the domain of the nursing of the aged, this nonverbal language is often used by a caregiver as a way to show love to the aged when giving the service of hand washing, helping the aged to stand up, or when leading the aged by hand to a place. In this video recording of Figure 4.3, is seen an Indonesian caregiver holding the hand of a grandfather (an old man) who was about to stand up. The caregiver was holding his hand while her other hand was holding the old man's walking equipment. The caregiver slowly and with full of love holding the old patient's hand, helping him to stand up and leading him by hand to the bath room.

The nonverbal language that is related to hand can express more things than a facial expression (Givens, David, 2002, p. 7). Hall \& Roter (2006), even call the holding of the patient's hand in many cases of nursing as something that functions ass patient healing. 


\section{Forward Leaning}

Givens (2002, p. 7-87) in the e-book The Nonverbal Dictionary of Gestures, Signs, and Body Language Cues explains that this nonverbal element is forward leaning by stooping or sitting closer to the patient to show attention or concern when on the way of making a journey. For example, offering something to the aged.

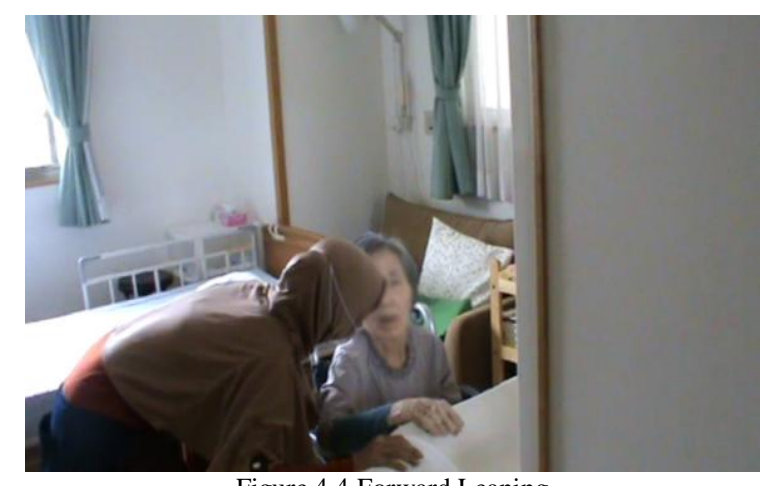

Figure 4.4 Forward Leaning

Figure 4.4 above shows a caregiver leaning her body forward when informing the aged that the activity after having a meal is brushing one's teeth. At the time of explaining this, the caregiver was leaning her body forward in front of the aged with the purpose of shown attention, and solidarity to her. This agrees with the explanation given by Nichizawa, et.al. (2006) that forward leaning can be used to show one's attention, solidarity, even love to the interlocutor.

\section{E. Lowering Body Position}

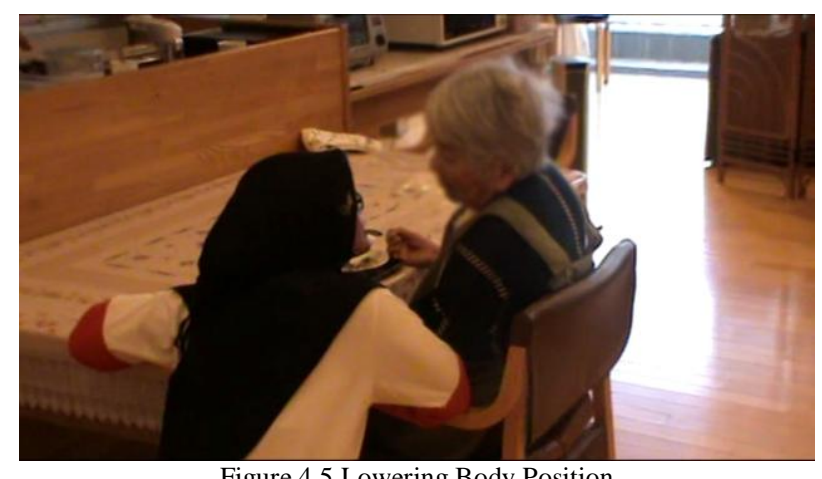

Figure 4.5 Lowering Body Position

Figure 4.5 shows an Indonesian caregiver squatting in front of an old patient. Givens (2002, p. 7-87) in the e-book The Nonverbal Dictionary of Gestures, Signs, and Body Language Cues explains that this nonverbal element is known as lowering body position. In the context of the figure above, the caregiver was approaching the patient who was enjoying her lunch. The caregiver asked whether the patient's stomach condition was getting better or not. Then the caregiver took a squatting position to make her position at the same level as the patient as a way of showing respect and empathy to the old patient (Gilbert, 1993).

\section{F. Affirmative Nodding}

This type of nonverbal language is nodding more than once as the sign of paying attention or strengthening words uttered (Givens, 2002, p. 7-87) in the e-book The Nonverbal Dictionary of Gestures, Signs, and Body Language Cues.

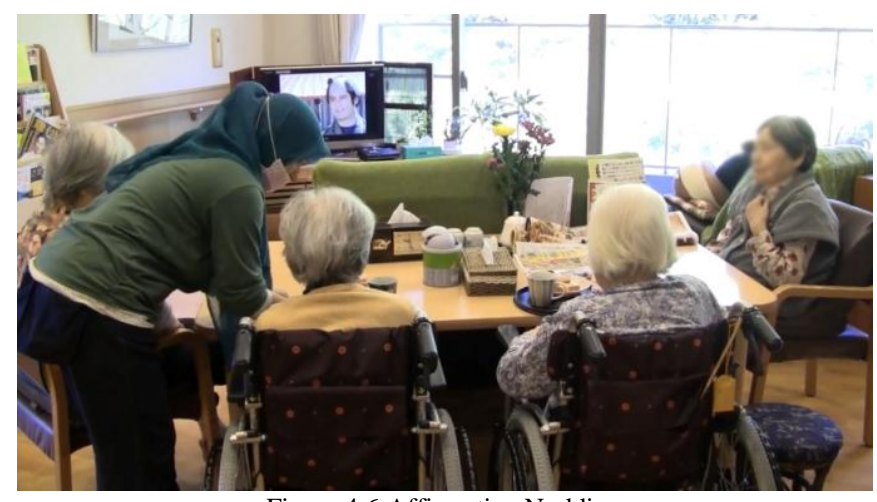

Figure 4.6 Affirmative Nodding 
If the video recording in Figure 4.6 is closely observed, a caregiver is seen bringing one of the old women a breakfast. The caregiver is nodding several times to show that she paid attention to the old woman's request at the time the latter was complaining because she did not want to eat porridge, and expressed her choice of wheat bread for breakfast. After nodding, the caregiver gradually explained that with her stomach problematic condition, porridge was the appropriate breakfast for the patient.

In a research done by Nichizawa (2006), it is also mentioned that affirmative nodding can develop trust and bring calmness.

\section{G. Gesture}

Gesture that is followed by a change of the other hand is usually made by a caregiver to express ideas, concern, attention, and emotion nonverbally (Hall \& Roter, 2006). In the domain of nursing the aged, the gesture followed by hand movement as observed in the three cuts of Figure 4.7 below is often done at the time of helping the aged to use an apron at time of eating. This gesture shows the caregiver's concern about the aged, showing love and intimate relation (Gilbert, 1993).
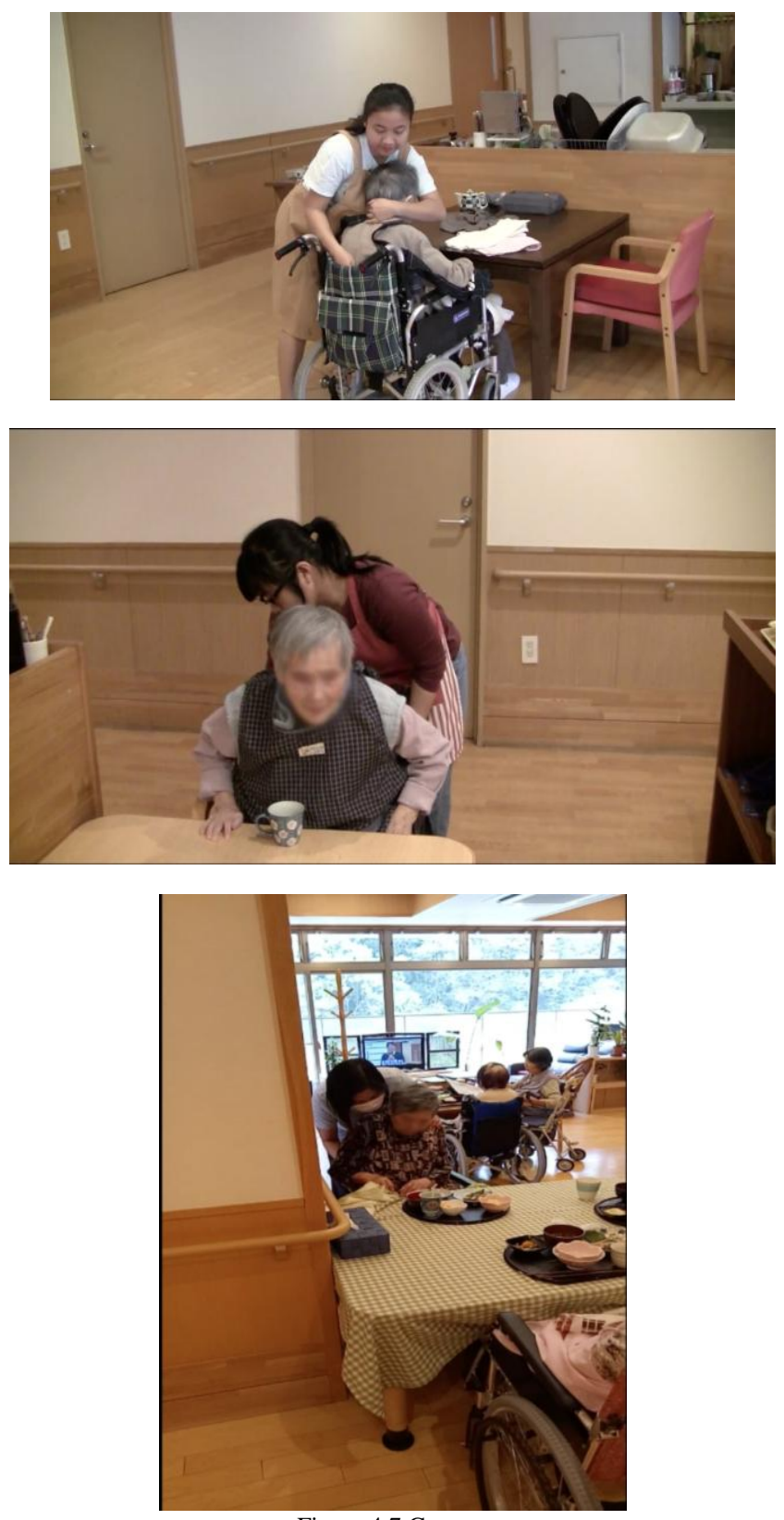

Figure 4.7 Gesture

\section{H. Hugging}

Givens (2002, p. 7-87) in the e-book "The Nonverbal Dictionary of Gestures, Signs, and Body Language Cues" explained that this nonverbal element is defined as a movement which gets the body of the patient closer to the 
caregiver or the caregiver is holding the patient's hand. In the domain of nursing the aged, this nonverbal language is often used when helping the aged to walk by hugging the aged while leading the latter walk like what is seen in Figure 4.8. It is aimed to help the aged to walk since the aged patient who has been old has difficulty of walking.

The video recording shows that an Indonesian caregiver was helping the aged to walk to the dining room by hugging her body and helping her to walk step by step carefully.

From the interviews with the Indonesian caregivers a new fact about old people's homes in Japan was revealed, that is, wheelchairs are only used by aged patients who are in a physically weak condition, those with disabled leg or who are ill. Aged patients with a good health condition have to try to walk alone. For example, by holding the wall, or by being hugged or supported by a caregiver. This is intended to keep their legs from stiffness because of the use of a wheelchair.

This explanation is also found in the book entitled Gaikokujin no tame no Kaigo Fukushihi published by Asosiasi Berbadan Hukum Umum Pertukaran Internasional dan Pendukung Bahasa Jepang (General Corporate Body Association of International Exchanges and Supporter of Japanese) in 2011. In this book is mentioned that Indonesian caregivers have to help aged patients to walk (imamori) by hugging, supporting or leading them by hand.

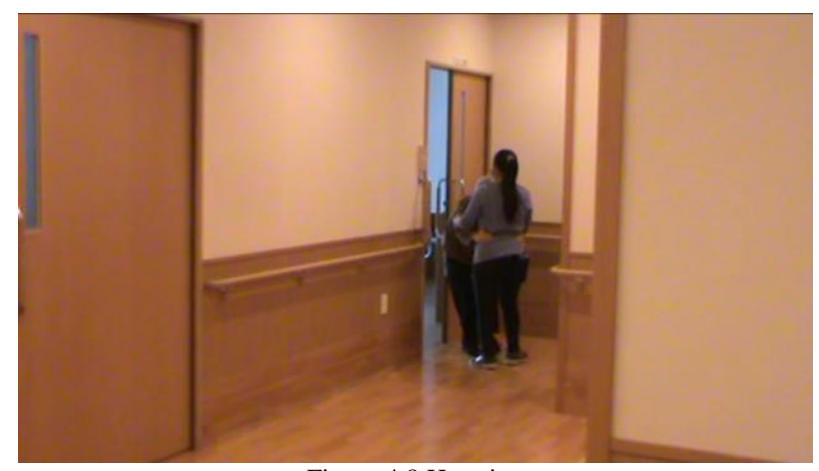

Figure 4.8 Hugging

\section{Interpersonal Space}

Givens (2002, p. 7-87) mentions that this nonverbal is defined as the position of a caregiver and an aged patient with a distance no more than three feet (very close). This nonverbal element can be done by sitting in a very close distance to the patient to give a secured and comfortable feelings to the aged.

In the domain of the nursing of the aged, this nonverbal is usually shown when feeding the aged or just when accompanying the aged to engage in a conversation. Figure 4.9 below depicts a situation when an Indonesian caregiver was persuading an aged patient to eat a snack or pudding. At that time the caregiver approached the aged who was watching TV, sitting close to her and then persuading her by saying that the pudding that the caregiver was holding was a gift from the aged patient's daughter that the aged patient had to eat. Hearing this, the aged patient smiled, nodded and wanted to open her mouth to eat the pudding.

Sometimes in the process of giving the service to the aged, a caregiver has to position the aged like a small child who has to be persuaded, fed, and accompanied to eat. Making a distance according to Gilbert (1993) is used to produce comfort and to give a feeling of freedom from intimidation.

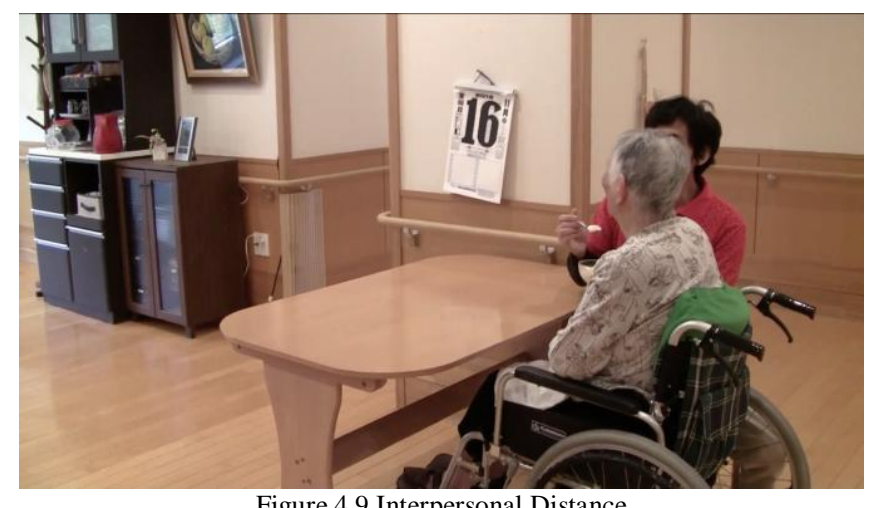

Figure 4.9 Interpersonal Distance

\section{J. Therapeutic Touch}

Givens (2002, p. 7-87) explains that this nonverbal element is a spontaneous physical contact with an aged patient by a caregiver. In giving a service to an aged patient, the nonverbal language of touch is often used by a caregiver as a way to show warmness, so that the aged patient does not feel being intimidated because of the presence of the caregiver and 
the service given by the caregiver. This touch is usually used to support the verbal language and can occur in many occasions of nursing. The figures below depict therapeutic touch.

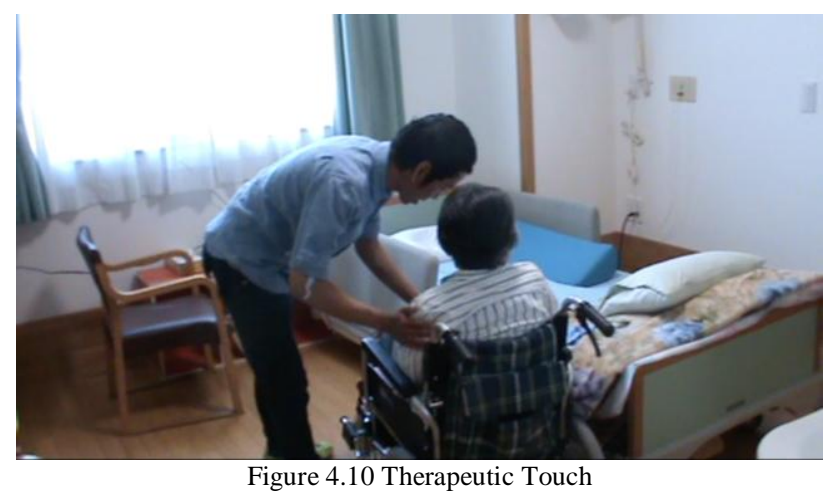

This figure above shows a caregiver touching the shoulder of an aged patient with an affection while helping the patient to lie down on the bed. A therapeutic touch on the patient's shoulder or arm is aimed at causing the feeling of comfort in the patient who is being served. This is in line with the explanation given by Hall \& Roter (2006) that a touch can speed up patient healing.

\section{K. Patting Shoulder}

Givens (2002, p. 7-87) defines this nonverbal language as the action of patting the aged patient's shoulder spontaneously as a realization of giving a praise or to promote the feeling of self-confidence of the aged when he or she is going to do something.

If Figure 4.11 is closely observed, there appears a caregiver who is accompanying an aged patient to enjoy eating lunch by sitting with knees bent and folded back to one side beside an aged patient. At the time the aged patient is finishing the food quickly, the caregiver is spontaneously patting the shoulder of the patient while sayingwaa..yatta...owatta...takusantaberebagenkininattayo which contains the meaning of praise to the aged patient.

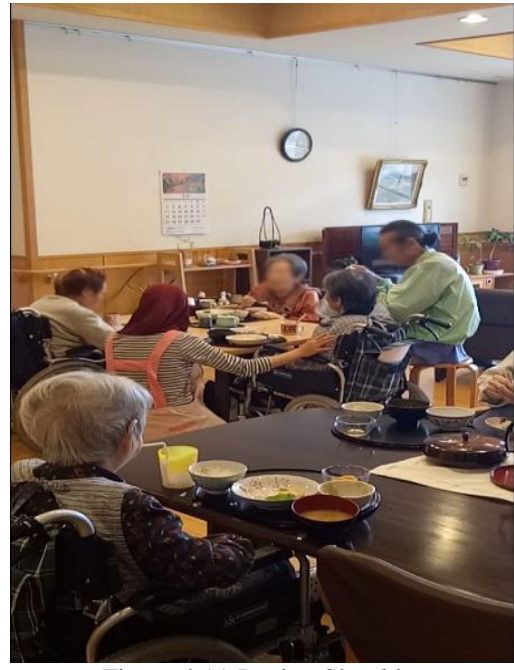

Figure 4.11 Patting Shoulder

This nonverbal element, according to Hall \& Roter (2006) functions as patient healing, that is promoting the patient's self-confidence.

From the eleven nonverbal elements found in this study, all of them were able to save the face of the aged. All of the eleven nonverbal elements promoted the feeling of comfort, reduced intimidation, and stiffness in the process of awkwardness in the interaction process between the Indonesian caregivers and the aged patients. The tabooed nonverbal elements in Japanese culture such as eye contact can be accepted in the domain of the nursing of the aged. Even in certain scenes which contain a refusal of the aged patients' request, the presence of nonverbal language can reduce the feeling of displeasure on the part of the aged patients for the refusal.

\section{CONCLUSION}

From the discussion above, it can be concluded as follows:

1. The use of nonverbal elements in the communication process between the caregivers and the aged patients can help patient's healing process. 
2. Nonverbal language can describe the emotional condition and express an interpersonal attitude.

3. Nonverbal language supports the use of verbal language and can also serve to replace verbal language in a situation in which the use of the verbal language is considered as something difficult for communicating a message.

4. The nonverbal symbols are reflections of our feelings and responses when we are reacting.

5. Nonverbal messages cannot be separated from verbal messages.

6. Nonverbal elements are generally more general than verbal words.

7. The meaning and interpretation of a nonverbal element is seen from the context of the situation of the utterances.

8. The expression of a message will be more effective if nonverbal elements are used.

\section{ACKNOWLEDGEMENTS}

This article is the fourth article written from the PKPI 2018 program funded by the Ministry of Research Technology and Higher Education. Thus, the writer would like to thank the Ministry of Research Technology of Higher Education for the opportunity given her to join the PKPI 2018 program. The writer would like to thank and appreciate those who have contributed to this current study, especially the supervisors: Prof. Dr. N.L. Sutjiati Beratha, M.A.; Prof. Dr. Made Budiarsa, M.A.; Prof. Dr. I Nengah Sudipa,M.A. for their criticisms, comments and suggestions. Thanks are also expressed to Prof. Eishi Hirose for the guidance in improving this article during the process of joining the PKPI 2018 program or Sandwich Like Program 2018 at Shizuoka University of Art and Culture, Japan.

\section{REFERENCES}

[1] Brown, P. dan Stephen C. Levinson. (1978). Politeness: Some Universals in Language Usage. Cambridge: Cambridge University Press.

[2] Cutting, J. (2002). Pragmatics and Discourse, A Resourse Book for Students. London : Routledge.

[3] Chaer, Abdul. (2010). Kesantunan Berbahasa. Jakarta : Rineka Cipta.

[4] Ekman, P., and W.V.Friesen. (1975). Unmasking the Face. Englewood Cliffs: Spectrum-Practice Hall.

[5] Gilbert, D.A. (1993). Reciprocity of Involvement Activities in Client Nurse Interactions. Western Journal of Nursing Research, 15 (6), 674-687. Accessed on 22 October, 2018.

[6] Gilbert, D.A. (2004). Coordination in Nurses Listening Activities and Communication about Patient-Nurse Relationships. Research in Nursing \& Health, 27 (6), 447-457.

[7] Hall, J.A., Roter, D.L. (2006). Physician- Patient Communication. In H, S. Friedman \& R. Cohen Silver (Eds.), Foundation of Healtsh Psychology (pp.325-357). Cary. NC: Oxford University Press.

[8] Hamiru, Aqui. (2004). 70 Japanese Gestures No Language Communication. Japan: IBC Publishing.

[9] Kendon, Adam. (1981). Introduction: "Current issues in The Study of Nonverbal Communication". In Nonverbal Communication Interaction and Gesture. Ed. Akendon.pp.1-53. The Hague: Mouton.

[10] Nichizawa, Y., Saito, M., Ogura, N., Kudo, S., Saito, K., \&Hanaya, M. (2006). The Nonverbal Communication Skills and Nursing Students: Analysis of Interpersonal Behaviour using Videotaped Recording in a 5- Minute Interaction with a Simulated Patient. Japan Journal of Nursing Science, 3, 15-22. Accessed on 22 October, 2018.

[11] Pranowo. (2012). BerbahasaSantun. Yogyakarta: PustakaPelajar.

[12] Simpen, I W. ( 2008). "Kesantunan Berbahasa pada Penutur Bahasa Kambera di Sumba Timur" (disertasi). Tidak Diterbitkan. Denpasar:Universitas Udayana.

[13] Wharton, Tim. (2009). Pragmatics and Non-Verbal Communication. New York: Cambridge University Press.

Putu Dewi Merlyna Yuda Pramesti was born in Singaraja, Bali, Indonesia. She is a Japanese education lecturer in Ganesha University of Education. She obtained her Master's degree in Linguistics in 2008 from Udayana University, Bali, Indonesia. She is currently a doctorate candidate in Linguistics at Udayana University and her main research is focused on Linguistics and Pragmatics.

Ni Luh Sutjiati Beratha is a Professor in Linguistic at Udayana University, Denpasar, Bali, Indonesia. She received her Master of Arts (M.A)'s degree in Linguistics from Monash University Australia in 1989, and her Doctor of Philosophy (Ph.D)'s degree in Linguistics from The Australian National University, Australia. She has supervised many theses and doctorate dissertations. She has participated in numerous national and international conferences and has written a lot of books and articles.

Made Budiarsa is a Professor in Linguistics of Udayana University, Bali, Indonesia. He obtained his Master of Art (M.A)'s degree in Linguistics from Sydney University in 1988, and his doctor's degree from Gajah Mada University, Indonesia in 2006. He has published many articles and books. His research interests are pragmatics and sociolinguistics. He has participated in many national and international conferences and workshops.

I Nengah Sudipa is a professor in Linguistics at Udayana University, Denpasar, Bali, Indonesia. He received her Master of Arts (M.A)'s degree in Linguistics from Monash University Australia in 1988, and his doctor's degree in Linguistics from Udayana 
University, Bali, Indonesia in 2004. He has been a supervisor from numerous thesis and doctorate dissertations. He has published many articles and books, and actively participated in national and international conferences. 